\title{
CRISIS ALIMENTARIAS EN CATALUÑA: 1092-1096
}

\author{
JORDI GUNZBERG MOLL ${ }^{1}$
}

Fecha de recepción: octubre 2001

Fecha de aceptación y versión final: diciembre 2001

Resumen: El hambre que afectó a Cataluña entre los años 1092 y 1096 supuso la primera gran crisis alimentaria generalizada que se conoce en todo el Principado. A partir de documentos privados procedentes de Barcelona, Gerona y la Seo de Urgel, se intenta reconstruir el marco territorial y cronológico de esta crisis, cuyo origen fue la falta de productos panificables.

Palabras clave: historia de la alimentación, Cataluña, siglo XI, hambres.

Abstract: The famine which affected Catalonia between 1092 and 1096 supposed the first big and generalized nourishment crisis known about all over Catalonia. Starting from private documents coming from Barcelona, Girona and La Seu d'Urgell we have tried to reconstruct the territorial and chronological setting of this crisis, which was originated by the lack of btead-making products.

Key-words: foodstuffs history, Catalonia, 11th Century, famines.

\section{SUMARIO}

I. Introducción.- II. Las crisis agrarias entre los años 1092-1096.- III. Ćrisis en otros sectores.-IV. Conclusiones.- Apéndice documental.

${ }^{1}$ Facultat de Dret, Universitat Pompeu Fabra. Barcelona.

«Anuario de Estudios Medievales», 32/1 (2002), pp. 3-18 .- ISSN 0066-5061. 


\section{INTRODUCCIÓN ${ }^{2}$}

En Europa durante la alta Edad Media son frecuentes las hambrunas y calamidades. Mayoritariamente fueron provocadas por crisis agrarias que, además de afectar a ámplias capas de la población, también causaron graves convulsiones sociales. En mayor o menor medida, todos los territorios padecieron la falta de alimentos y, en consecuencia, Cataluña no fue ajena a esta realidad. De todas las crisis alimentarias que azotaron el Principado en este período, sin lugar a dudas, una de las más importantes fue la padecida entre los años 1092 y 1096.

Hay tres zonas del territorio catalán con noticias directas de hambrunas; concretamente en las poblaciones de Barcelona, Girona y la Seu $\mathrm{d}^{\prime}$ Urgell ${ }^{3}$. Esta extensión territorial en unos años tan concretos hace pensar

${ }^{2}$ Siglas más utilizadas: $\mathrm{ACB}=$ Archivo de la Catedral de Barcelona, $\mathrm{ACA}=$ Archivo de la Corona de Aragón, $\mathrm{ACG}=$ Archivo Capitular de Girona, $\mathrm{ACU}=$ Archivo de la Catedral de Urgell, $\mathrm{ADB}=$ Archivo Diocesano de Barcelona, $\mathrm{ADG}=$ Archivo Diocesano de Girona, LA I= Liber Antiquitatum volumen I, RB III = Ramón Berenguer III, carp. = carpeta, núm. = número, perg. = pergamino, ss. $=$ siglos

${ }^{3}$ Referente a las ciudades y territorios de Barcelona, Girona y Seu d'Urgell (siglos VIII-XII): $\mathrm{Ph}$. BANKS, The topography of the city of Barcelona and its urban context in eastern Catalonia from the third to twelfth centuries, University of Nottingham, 1980 (tesis doctoral inédita). Se ha publicado parcialmente en: L'estructura urbana de Barcelona, 714-1300. En "História de Barcelona. La formació de la Barcelona medieval". Barcelona, Enciclopedia Catalana/Ajuntament de Barcelona, vol. 2, pp. 26-71. También del mismo autor The north-western gate of the city of Barcelona in the 11th. and 12 th. centuries, "Cuadernos de Arqueologia e Historia de la Ciudad", XVII (Barcelona, 1977), pp. 117-127; "Burgus", "suburbium" and "vilanova". The extramural growth of Barcelona before a.d. 1200, "Actes del II Congrés d'Història del Plà de Barcelona, celebrat a l'Institut Municipal d'Història, 6 i 7 desembre de 1985", Barcelona, Ajuntament de Barcelona, 1990, pp. 107-133; The inhabitants of Barcelona in 1145, "Acta Historica et Archeologica Medieavalia", 9 (Barcelona, Universitat de Barcelona, Facultat de Geografia i Història, 1988), pp. 143-166; J.E. RUIZ DOMÈNEC, Las estructuras familiares catalanas en la alta Edad Media. Introducción al estudio de la formación y evolución de los sistemas de parentesco en la nobleza, el campesinado y los cuadros urbanos, "Cuadernos de Arqueología e Historia de la ciudad", XVI (Barcelona, Ayuntamiento de Barcelona, 1975), pp. 69-123; La sociedad barcelonesa en los siglos XI y XII, Universidad de Barcelona, 1973 (tesis doctoral inédita); El desarrollo de la economía monetaria. La crisis de los pequeños propietarios libres durante los siglos XI y XII en el condado de Barcelona, "Miscellania barcinonensia", XXXVIII (Barcelona, Ayuntamiento de Barcelona, 1974), pp. 17-67; Ricard Guillem un sogno per Barcellona, Napoli, Edizioni Athenea, 1997; S.P.BENSCH, Barcelona et its rulers 1096-1291, Cambrige, Cambrige University Press, 1995; P. BONNASSIE, Catalunya mil anys enrera. Segles $X-X I$, Barcelona, Edicions 62, 2 vol., 1979-1981; F. CARRERAS CANDI, Geografia General de Catalunya. La ciutat de Barcelona, Barcelona, vol. II, s.d.; G. FELIU I MONTFORT, La toponimia del Plà de Barcelona al segle X, "Actes del I Congrés d'História del Pla de Barcelona, celebrat a l'Institut Muinicipal d'Història, els dies 12 i 13 de novembre de 1982", Barcelona, Edicions la Magrana, 1984, pp. 101-112; Els inicis del domini territorial de la Seu de Barcelona, "Cuadernos de Historia Economica de Cataluña", Barcelona, Facultad de Ciencias Económicas y Empresaria- 
que pudiera tratarse de una única crisis. Sin embargo, la amplitud del período pone en duda esta hipótesis. Sí puede afirmarse que se trata de una amplia crisis alimentaria y que afectó tanto a la Cataluña cristiana como a otros territorios europeos, incluso algunos muy alejados.

A partir de siglo XI, los cereales se convierten en la base de la alimentación para la mayor parte de la población urbana. El bosque empieza a perder la importancia que había adquirido siglos anteriores. Lo cierto es que se ha producido una degradación bastante generalizada en el monte mediterráneo y este hecho afecta de manera primordial a una población como

les de la Universidad y del Instituto Muncipal de Historia de Barcelona (marzo 1976), pp. 45-61. M. FERnÁNDEZ, F.X. HernándeZ, A. SuÁrez, M. TATJER, M. VIDAL, Passat $i$ present de Barcelona (1). Materials per a l'estudi del medi urbà. Barcelona, Universitat de Barcelona, Col-lecció Pau Vila, núm. 4, 1983; A. GarCía I EspuCHE, M. GuARDIA I BASSOls, Espai $i$ societat a la Barcelona pre-industrial, Edicions de la Magrana, Ajuntament de Barcelona, Institut Muncipal d'Història, 1986.

C. BATLlE I GALLART, La Seu d'Urgell medieval: La ciutat $i$ els seus habitants, Barcelona, Fundació Salvador Vives Casajuana, 1985; IDEM, Evolución de una ciudad catalana: la Seu d'Urgell en la Edad Media, "Estudios Medievales", IV (Homenaje a D. José María Lacarra), Zaragaoza, 1977, pp. 175-190. También Els orígens medievals de la Seu d'Urgell, "Episodis de la Història", núm. 235; Els orígens medievals i l'evolució urbana de la Seu d'Urgell, "Urgellia", 2 (1979), pp. 151-167; Les institucions benèfiques de la Seu d'Urgell durant l'Edat Mitjaná (segles XI-XV), "Urgellia", 6 (1983), pp. 285-335; C. BARAUT, Presència i repressió del catarisme al bisbat d'Urgell (segles XII-XIII), "Urgellia", 12 (1994-1995), pp. 487-525; El lloc de Ciutat, primitiu nucli urbà de la Seu d'Urgell, de l'època romana a la fi de l'edat mitjana, "Urgellia", 8 (1986-1987), pp. 483-493; La data de l'acta de consagració de la catedral carolíngia de la Seu d'Urgell, "Urgellia", 7 (1984-1985), pp. 515-531; Catalunya Romànica. Alt Urgell, Andorra, vol. VI, Barcelona, Enciclopèdia catalana, 1992; A. GRIERA, Las parroquias de la Seo de Urgel, "Boletín de Dialectología Española", XXXVIII, San Cugat del Valles, pp. 5-67; E. MOLINÉ, El "Compendi històric" i els primers assaigs d'historia de l'esglesia d'Urgell (segles XVI $i$ XVIII), "Urgellia", 12 (1994-1995), pp. 425-481; M. PUIG FERRETER, L'ascendència pallaresa dels bisbes d'Urgell Bernat Guillem (1076-1092) $i$ Guillem Arnau de Montferrer (1092-1095), "Urgellia". Seu d'Urgell, vol. III, pp. 185-194. M.A. RUF- A. VILlARÓ, L'esglèsia romànica de Santa Eulàlia de la Seu d'Urgell, "Urgellia", núm. 11 (19921993), pp. 487-511.

R. AlBERT-N.J. ARAGÓ, Els jueus de les terres gironines, "Quaderns de la Revista de Girona", 1 (Girona, 1985); X. BARRAL I ALTET, L'art pre-romànic a Catalunya. Segles IX-X, Barcelona, Edicions 62, 1981; C. BASTIT-M.T. GENIS-J.M. LlORENS-A. RoDRíGUEZ, Les intervencions arqueològiques a la Plaça de Sant Feliu (Girona), "Tribuna d'Arquelogia", Departament de Cultura de la Generalitat de Catalunya, pp. 91-98; Girona dins la formació de l'Europa medieval 785-1213, Girona, Museu d'Història de la Ciutat, Ajuntament de Girona, 1975; Catalunya romànica. El Gironès, la Selva i el Pla de l'Estany, Barcelona, Enciclopedia Catalana, vol. V, 1991; J. MARQUĖS I CASANOVAS, Importantes hallazgos arqueológicos en la catedral de Gerona, "Revista de Gerona", VI/14, pp. 39-44; J. MARQUĖS I CASANOVAS-J.M. MARQUĖS I PLANAGUMÀ, Apuntes históricos sobre el Palacio Episcopal de Gerona, "Anales del Instituto de Estudios Gerundenses", XIV, pp. 263-306; J.M. NoLLA, El sector oriental de les muralles de Gerunda. Noves aportacions al seu coneixement, "Cypsela", VII (Girona), pp. 111130; Noticias sobre iglesias prerromanicas gerundenses, "Revista de Gerona", 20 (Girona), pp. 65-89; J. PLA CARGOL, La Torre Gironella, "Anales del Instituto de Estudios Gerundenses", I (Girona), pp. 108-116. También Proceso del desarrollo urbano de Gerona a través de los tiempos, "Anales del Instituto de Estudios Gerundenses", II (Gerona, 1957), pp. 209-228. 
Barcelona. Por contra, la Seu d'Urgell mantiene un espacio boscoso mucho más íntegro.

Es sintomático valorar las noticias que en estos tres territorios aparecen sobre las crisis de subsistencia. Barcelona es la localidad donde más veces aparecen crisis alimentarias, mientras que de la Seu d'Urgell, para este período, sólo aparece una referencia.

Tradicionalmente, los historiadores coinciden en afirmar que a finales del siglo X y principios del siglo XI, en Cataluña, hay un incremento demográfico, desarrollándose la producción y expandiéndose la superficie cultivada. En Barcelona, se produce una importante llegada de moneda extranjera de oro. Como consecuencia, habrá una fiebre compradora de bienes muebles e inmuebles con una subida ininterrumpida de precios. La máxima expansión tiene lugar en la década de los años 1050-1060, situación que se mantendrá hasta el año 1080. También importante será el movimiento de construcción que durará hasta finales de la Edad Media.

Ya en el siglo X, Girona se va consolidando como un centro urbano y económico, como lo demuestran la acuñación de moneda y la celebración ferias y mercados periódicos. También destaca el impulso constructor que tiene como máximo exponente la consagración de la catedral en el año 1038. Se tiene constancia de que la canónica disponía de casas privadas donde residían algunos sacerdotes, semejante a lo que ocurría en Barcelona. Durante la primera mitad del siglo XI, se construye, además del monasterio de Sant Daniel, la iglesia de Sant Martí Sacosta. Con posterioridad, se edificará el claustro catedralicio. Poco a poco, van creciendo los barrios de Sant Pere y del Mercadal. Se extienden las defensas de la ciudad; se construye la Torre de la Gironella y se edifica una nueva muralla. En el siglo XII, se amplian algunas barriadas como Pedret, prolongación de Sant Pere. Asimismo, destaca la construcción del un centro asistencial conocido como Hospital Vell.

La Seu d'Urgell tiene una gran desarrollo durante el siglo XI. Conquistada por los francos hacia el 785 y destruida en diversas ocasiones, comienza a desarrollarse al inicio del segundo milenio. La construcción de la catedral de Santa Maria tiene como punto álgido el impulso del obispo San Ermengol y la protección de los condes. Ejemplos de este afán constructor son el nuevo templo catedralicio consagrado en el 1040 y la edificación de iglesias y puentes. Otro ejemplo de esta renovación urbana son las periódicas celebraciones de mercados y ferias y la fundación en el 1059 de un hospital de los pobres, institución creada testamentariamente a través de la cesión de 
unas casas. En el año 1092, se crea otra forma de asistencia, la hermandad de Sant Miquel como una institución caritativa.

El conocimiento que entre dichos años se producen hambrunas de gran intensidad procede mayoritariamente de las crónicas monásticas. Se trata de notas muy parcas, poco explicativas y con frecuencia catastróficas. Por tanto, necesariamente se han de consultar los documentos privados, mucho más objetivos y realistas, porque la crisis obliga a los habitantes a realizar una serie de actos jurídicos para satisfacer la necesidad de adquirir alimentos ${ }^{4}$.

${ }^{4}$ Concretamente para este período podemos encontrar algunas referencias a crisis alimentarias como son el Cronicon altera Rivipullense (a). J.L. VILLANUEVA, Viage literario a las Iglesias de España, vol. V, Madrid, 1806, pp. 236-249. Otras hambrunas en las crónicas Agustini y Hildesheimenses, recogidas por Robert R. NEWTON, Mediaeval Chronicles and the Rotation of the Earth. Londres, 1972.

Para la ciudad y territorio de Barcelona se han publicado una serie de materiales documentales que nos han servido como referencia a la hora de identificar y analizar los años de crisis: $J$. Alturo PeruCho, L'arxiu antic de Santa Anna de Barcelona del 942 al 1200. Aproximació al històric-lingüística, Barcelona 1985. 3 volums; A. FÀBREGA GRAU, Diplomatari de la Catedral de Barcelona: Documentes del ss. IX-XIII: anys 844-1260. Volum I: Documents dels anys 8441000. Barcelona, Catedral de Barcelona, 1995. G. FELIU i J.M. SALRACH (direc). Els pergamins de l'Arxiu Comtal de Barcelona de Ramon Borrell a Ramon Berenguer I, 3 vols. Barcelona, Fundació Noguera, 1999; J. MAS I DOMENECH, Rúbrica dels "Libri Antiquitatum" de la Seu de Barcelona, "Notes històriques del bisbat de Barcelona". Barcelona, 1914-1915, 4 vols. P. PuIG I USTRELL, El monestir de Sant Llorenc de Munt sobre Terrassa. Diplomatari dels segles Xi XI, 3 vols., Barcelona, Fundació Noguera, 1992; A. UdINA, La successió testada almedieval a Catalunya, Barcelona, Fundació Noguera, 1984.

Referente a la Seu d'Urgell se ha de destacar la colección diplomática del archivo capitular, publicados en los trece volúmenes de la revista "Urgellia". P. Cebrià BARAUT, Els documents dels any 1093-1100, de l'Arxiu Capitular de la Seu d'Urgell, "Urgellia", Seu d'Urgell, VIII (La Seu d'Urgell, 1986-1987), pp. 7-149. También Cartulari de la Vall d'Andorra. Segles IX-XII. Andorra: Govern d'Andorra, vol. I, 1988. Diplomatari del monestir de Sant Climent de Codinet (segles IX-XI) "Subsidia Monastica", 9 (Abadia de Montserrat), pp. 241-271. J. SOLER I GARCIA, Cartulario de Tavernoles, "Boletín de la Sociedad Castellonense de Cultura", XXXVI (Castelló de la Plana, 1960), pp. 197-279; vol. XXXVIII, (1961), pp. 65-80; vol. XXXVIII, (1962), pp. 428-442; vol. XXXIX, (1963), pp. 59-76. P. PUJOL, Documents en vulgar dels segles XI, XII $i$ XIII procedents del bisbat de la Seu d'Urgell amb un pròleg $i$ un fascimil. "Biblioteca Filológica", Barcelona, (1913), pp. 1-50.

Para la ciudad y territorio de Girona: LL. G. Constans i M.D. SERRATS, Diplomatari de Banyoles (De l'any 1051 al 1299). vol.II. Banyoles, Centre d'Estudis Comarcals de Banyoles (Secció d'Estudis Medievals), 1987; J.M. MARQUÈs, Col-lecció diplomàtica de Sant Daniel de Girona (924-1300), Barcelona, Fundació Noguera, 1997; J.M. MARQUĖs I PlaNAGUMÃ, El cartoral de Santa Maria de Roses (segles X-XIII), Barcelona, Institut d'Estudis Catalans, 1986; J.M. MAROUĖS, Cartoral dit de Carlemany, del bisbe de Girona (s. IX-XIV), Barcelona, Fundació Noguera, 2 vols., 1993; R. MARTí, Col-lecció diplomàtica de la Seu de Girona (817-1100), Barcelona, Fundació Noguera, 1997; E. PRUENCA BAYONA, Diplomatari de Santa Maria d'Amer, Barcelona, Fundació Noguera, 1995. F. MonSAlVATJE I FosSAS, Colección diplomática del condado de Besalú, en "Memorias históricas", Olot, Imprenta y Librería de Juan Bonet, vols. 8, $11,13,15$ y 19; J.M. Pons GuRI, El Cartoral de Santa Maria de Roca Rossa, Barcelona, Fundació Noguera, 1984.

También R. ORDEIG I MATA, Inventari de les actes de consagració i dotació de les esglèsies catalanes IV. Anys 1051-1100, "Revista Catalana de Teología", IX/1 (Barcelona, Facultat de Teologia), pp. 117-182. 
Sobre la bibliografía, se ha de descatar que hay pocos estudios en torno a las crisis de subsistencia agraria altomedievales y, aún menos, por lo que se refiere al ámbito territorial catalán. En todo caso, en los últimos años, han aparecido algunas investigaciones que bien directa o indirectamente citan dicha crisis ${ }^{5}$.

${ }^{5}$ Sobre las crisis altomedievales, se pueden consultar como bibliografía general:

A. ABEL, Crisis agraires en Europe $\left(X I I^{e}-X X^{e}\right)$, Paris, 1973; A.M. BAUTIER, Pain et pattisserie dans les textes medievaux latins antérieurs au XIII siècle, en "Manger et boire au Moyen Âge. Actes du Colloque de Nice (15-17 octobre 1982)", Nice, Faculte des lettres et sciences humaines, vol. I, 1984, pp. 33-65; J.O. BENOIST, Le gibier dans l'alimentation seigneuriale $\left(X I^{e}-X V^{e}\right.$ siècles), en "Manger et boire au Moyen Âge", citado, I, pp. 75-84; P. BONNASSIE, Consommation d'aliments immondes et cannibalisme de survie dans l'Occident du Haut Moyen Âge, "Annales Économies, Societes, Civilisations", 5 (Paris, septembre-octobre 1989), pp. 1035-1056; I. CONDÉS I SANGRENÍs, Els aliments a la regla de Sant Benet, en "I Col·loqui d'història de l'alimentació a la Corona d'Aragó", Lleida, Institut d'Estudis Ilerdencs, 1995, pp. 421-427; G. DUBY, Economia rural y vida campesina en el Occidente medieval, Barcelona, editorial Península, 1973; C. HIGOUNET, Les forêts de l'Europe occidentale du $V^{z}$ au $X I^{e}$ siècle, pp. 343-397; J-C. HOCQUET, Le pain, le vin et la juste mesure a la table des moines carolingiens, "Annales ESC", 3 (Paris, mai-juin, 1985), pp. 661-689; I. IMBERCIADORI, Vite e vigna nell'alto medio evo, "Settimane di Studio Alto Medioevo", XIII, Spoleto, pp. 307-342; A.B. MARTINO, La comida y la bebida en los tiempos carolingios, en "Manger et boire au Moyen Âge", cit., II, pp. 183-195; P. MANE, L'alimentation des paysans en France et en Italie aux XII et XIII siècles a travers l'iconographie des calendriers (sculpture, fresques...), en "Manger et boire au Moyen Âge", citado, I, pp. 319-333; M. MoNTANARI, Alimentazione, cultura, società nel Medioevo, "Ir Col-loqui d'Història de l'Alimentació a la Corona d'Aragó", citado, pp. 21-37. También L'alimentazione contadina nell'alto Medioevo, Nàpols, Liguori Editore, 1979. Il ruolo della caccia nell'economia e nell'alimentazione dei ceti rurali dell'Italia del Nord. Evoluzione dell'alto a l basso medioevo, en "Manger et boire au Moyen Age", citado, I, 1984, pp. 331-337; El hambre y la abundancia. Historia y cultura de la alimentación en Europa, Barcelona, Editorial Crítica, 1992; N.J.G. POUNDS, La vida cotidiana: historia de la cultura material. Barcelona, Editorial Crítica; R.I. ROTBER-T.K. RABB, El hambre en la historia. El impacto de los cambios en la producción de alimentos y los modelos de consumo sobre la sociedad, Madrid, Editorial Siglo XXI, 1990; M. RouCHE, Le repas de fête a l'èpoque carolingienne. en "Manger et boire au Moyen Âge, citado, I, pp. 265-296.

Estudios centrados en la Península Ibérica:

C. LALIENA CORBERA, "Sicut ritum est in terra aragonensis": comidas rituales y formas de solidaridad campesina en el siglo XI, en "I $\mathrm{r} \mathrm{Col} \cdot$ loqui d'història de l'alimentació a la Corona d'Aragó. Edat Mitjana", citado, pp. 665-691; A.I. LAPEÑA PAÚl, Notas en torno al sistema alimentario en un monasterio altoaragonés en la Edad Media (El caso de San Juan de la Peña), en "La Mediterrània, àrea de convergència de sistemes alimentaris (segles V-XVIII)", Palma de Mallorca, Institut d'Estudis Baleàrics, 1996, pp. 379-391; MARTíNEZ SOPENA-J. CARBAJO SERRANO, L'alimentation des paysans castillans du XI au XIII' siècle d'après les "fueros", en "Manger et boire au Moyen Âge, citado, I, 1984, pp. 335-347; A. SESMA MUÑOZ, Aproximación al estudio del regimen alimentario del reino de Aragón en los siglos XI y XII, Homenaje a Don José María Lacarra de Miguel en su jubilación del profesorado. Estudios Medievales, Zaragoza, 1977, pp. 55-78.

En el ámbito catalán:

A. AULESTIA I PIJOAN, Barcelona ressenya histórica, Barcelona, 1976; P. BENITO MONCLÚS, Fams atroces a la Catalunya de l'any 1000, "Actes del Congrés Internacional Gerbert d'Orlhac i el seu temps: Catalunya i Europa a la fi del primer mil leni, Vic Eumo Editorial, 1999, pp. 189. 207; J.P. CANO, Evolució recent del paisatge vegetal a l'àrea de Barcelona (segles VI-XX), a partir d'analisis pol-liniques de sediments marins del Delta del riu Besós, Universitat Autònoma de Barcelona (tesis doctoral inèdita), 1994; J. GüNZBERG MOLL, Crisis agrarias, mortalidades 


\section{LAS CRISIS AGRARIAS ENTRE LOS AÑOS 1092-1096}

En Europa, las crónicas mencionan enfermedades y hambrunas durante este período. En el año 1094, se produce una gran mortalidad. Entre las noticias que mencionan este hecho, destacan las dificultades que tuvieron los obispos alemanes que regresaban del sínodo de Maguncia de acceder a la iglesia parroquial de Amberg, a causa del gran número de cadáveres que había en el suelo ${ }^{6}$. Otra fuente monástica dice que, en los años 1093 y 1094, se produce un período de hambres y enfermedades por todo el Imperio ${ }^{7}$. Según el Cronicón altera Rivipullense, en el año 1094, se sucedieron hambrunas por todo el mundo ${ }^{8}$. Para Montanari, se extiende por Europa una epidemia de ergotismo, con un brote de especial virulencia en $1094^{9}$. Asimismo, en el año 1095, vuelve a aparecer otro periodo de hambrunas ${ }^{10}$.

La crisis que padece el territorio catalán entre los años 1092-1096 se hace muy evidente por las noticias que nos dan los documentos privados. Es una información considerable tanto por lo que se refiere a su cantidad como

y alimentación en la ciudad y territorio de Barcelona, durante la alta Edad Media, "Anuario de Estudios Medievales", 30/2 (Barcelona, 2000), pp. 979-1013; J.M. PALET-S. RIERA MORA, Transformacions del paisatge en època alt-medieval (ss. X-XII) al sector de Montjü̈c-El port: una aproximació històrico-geogràfica, en "La ciutat i el seu territori, dos mil anys d'història. Actes del II Col·loqui d'História de Barcelona. Barcelona, octubre 1993, vol. I, pp. 181-194; J.E. RUIZ DOMÈNEC, The urban origins of Barcelona: agricultural revolution or commercial development? "Speculum", LII (Cambridge, Massachusetts, 1977), pp. 265-286. También El sentido de la riqueza en el condado de Barcelona en el siglo XI. Notas para su estudio, "Miscellania Barcinonensia", XIV/XLII (1975), pp. 17-33; Ramon Berenguer II Cap d'Estopes. Su concepto de gobierno. Universidad Autónoma de Barcelona (tesis doctoral inédita), La ciudad de Barcelona durante la Edad Media: De los orígenes a la formación de un sistema urbano, "Quaderns d'Arquelogia i Història de la Ciutat", XVIII (Barcelona, 1980), pp. 69-97. El origen del capital comercial en Barcelona, "Miscellania Barcinonensia", XI/XXXI (1972), pp. 55-88; Solidaridad familiar y organización de clanes en la ciudad de Barcelona en los siglos XI y XII, "Miscellanea Barcinonensia", XV/XLV (1976), p. 726; S. SOBREQUÉs VIDAL, Els grans comtes de Barcelona Barcelona, 1961; R. VIADER, Autour d'une practique juridique: les contracts agraires des archives capitulaires de Barcelona (XIe-XIIIe siècle), "Acta Historica et Archaeologica Medievalia", 16-17 (Universitat de Barcelona, 1995-1996), pp. 147-165.

${ }^{6}$ Cfr. M. MONTANARI, El hambre, op. cit., p. 49.

${ }^{7}$ Crónicas Agustini y Hildesheimenses. Citado por NEwTon, Medieval chronich, p. 698.

${ }^{8}$ P. Villanueva, Viage, op. cit., tomo V, p. 246.

${ }^{9}$ El hambre, op. cit., p. 50.

${ }^{10} \mathrm{P}$. BonNASSIE, Consommation, op. cit., p. 1044. 
a su calidad. Son en su mayor parte, documentos de ventas, aunque también aparecen permutas y donaciones.

La importancia de esta hambruna de fines del siglo XI viene confirmada en una carta de compraventa donde se manifiesta que abarca toda la tierra: propter fames valida que surrexit per circuitum nostrum iportabilia in omni terra ab Italia usque ad Sanctum Iacobum Gallecia ${ }^{11}$. En otro documento, se hace mención las grandes necesidades que hubo en el pasado: per plurimas fames qui fuerunt in patria Barchinone ${ }^{12}$.

Para poder subsistir, los habitantes utilizan diversas alternativas. La primera, adquirir dinero en metálico y utilizarlo para comprar alimentos, tal como hace Guillem Bonfill que vende un alodio situado en el territorio de Barcelona por 74 mancusos $^{13}$. Otra forma es obtener directamente los cereales: trigo y centeno. Bernat Radol y su mujer venden una viña a Ramon Arnau por un modio de trigo ${ }^{14}$. En cambio Ponç Ramon y su mujer Ermengarda permutan a los canónigos de la Seu unas tierras por un animal de tiro y 10 modios de centeno ${ }^{15}$. También que una institución religiosa, en este caso las canónicas de Barcelona y Urgell, se hagan cargo de la manutención. Bonfill Esteve cede a la catedral de Barcelona, por un año, un alodio a cambio de que le mantenga y le vista ${ }^{16}$.

Para adquirir alimentos, algunos habitantes venden su casa, tal como hace Petronila a Ramon Llopart y a Bernat Otger por un precio de 25 mancusos $^{17}$. Lo más habitual es ceder una tierra ${ }^{18}$, un alodio ${ }^{19}$ o unas viñas ${ }^{20}$.

Los términos utilizados en los documentos que nos indican la existencia de una crisis de subsistencia son: "necessitate famis", "fame

${ }^{11} \mathrm{ACU}$, perg. núm. 711

${ }^{12} \mathrm{ACA}, \mathrm{RB}$. III, perg. núm. 191

${ }^{13}$ ACB, LA I, núm. 496

${ }^{14} \mathrm{ACU}$, perg. núm. 750

${ }^{15} \mathrm{ACU}$, perg. núm. 711

${ }^{16} \mathrm{ACB}, \mathrm{LA}$ I, núm. 409.

${ }^{17} \mathrm{ACB}, 1-4-311$.

${ }^{18} \mathrm{ADB}$, carp. 34, perg. núm. 165.

${ }^{19} \mathrm{ACB}$, LA I, núm. 496.

${ }^{20} \mathrm{ACB}$. LA IV, núm. 121. 
intolerabili moriamur", "propter fames", "nimia calamitate", "inopiam fames", "ut eripiatis nos a miseria famis", "deinde cogente nimia necessitate", "sterilitatem fammis", y "plurimas fames".

Un análisis detallado de los documentos nos permite hacer una valoración espacial y cronológica de las crisis. Desde la primera perspectiva, tienen lugar hambrunas en Barcelona durante los años 1092, 1093 y 1094. En Girona, durante 1094 y 1095, mientras que, en Urgell, las crisis adquieren importancia en 1093, 1095 y 1096. Cronológicamente, la máxima incidencia tiene lugar en los años 1093, 1094 y 1095, destacándose, sin lugar a dudas, la gran subsistencia del año 1094. Un análisis que contemple al mismo tiempo el ámbito espacial y cronológico permite decir que la crisis del año 1092 puede catalogarse como local por el hecho de que sólo afecta a Barcelona, lo mismo sucede en el año 1093 y si bien los documentos mencionan que se extiende por todo el territorio catalán, únicamente hay constancia de la misma en la Seu d'Urgell. La hambruna del año 1094 puede considerarse como territorial al tenerse noticias de la misma tanto en Barcelona como en Girona. Otro tanto sucede con la crisis del año 1095, que afecta a las comarcas d'Urgell y Girona. Por último, en el año 1096, se menciona una hambruna local que se centra en el territorio de Urgell.

\section{CRISIS EN OTROS SECTORES}

La mayoría de autores que han estudiado la historia de Barcelona durante el siglo XI están de acuerdo en afirmar que, a partir de 1080, se inicia un periodo de crisis $^{21}$. Coincide con un repliege económico y social que durará unos quince años hasta la llegada de Ramon Berenguer III. Es un momento en que la estructura generacional se amplía y la solidaridad familiar actuará en los medios económicos urbanos ${ }^{22}$.

La crisis también afectó a las principales instituciones ciudadanas y más concretamente a las inversiones del dominio de la Seu de Barcelona. Los

\footnotetext{
${ }^{21} \mathrm{P}$. BENITO I MONCLÚs, Clergues, op. cit.; J.E. RuIz DoMÈnEC, Ramon Berenguer II Cap d'Estopa. Su concepto de gobierno. Tesis doctoral. Universidad Autómoma de Barcelona, 1971. También Solidaridad familiar, op. cit.; S. SOBREQUÉS VIDAL, Els grans comtes de Barcelona, Barcelona, 1961; S.P. BENSCH, Barcelona, op. cit.

${ }^{22}$ J.E. RuIz DOMÈNEC, Solidaridad familiar, op. cit., p. 20.
} 
beneficios generados por la vinicultura decaen considerablemente hecho que afectará a las rentas del capítulo.

También supone algunos cambios en la administración del patrimonio eclesiástico. En este período se prueba una nueva fórmula para atraer capitales a la Seu de Barcelona. La forma de hacerlo es a través de la cesión de bienes inmuebles a particulares a través del pago de un censo. También durante la hambruna de : los años 1092-1094, algunos eclesiásticos aprovecharon la circunstancia para adquirir la propiedades de diversos habitantes de la ciudad $^{23}$

Esta crisis tuvo resonancias posteriores. En el año 1116, Salomó Arimany y María dieron a su hijo Guifré una casa situada en el suburbio de Barcelona, como gratitud a los servicios prestados por su hijo en el periodo de carestía en Barcelona, ya que fue el único que les socorrió en esos díficiles momentos ${ }^{24}$.

\section{CONCLUSIONES}

Vistos los documentos y la información que existe sobre esta hambruna, podemos preguntarnos si hubo una o varias crisis de subsistencia. Ante este dilema, decir que no hay una respuesta definitiva, aunque se puede aventurar la existencia de diversas crisis, algunas de las cuales pudieran ser la misma en el transcurso de dos o tres años.

La repercusión de las hambrunas altomedievales son evidentes. No hay que llegar hasta el siglo XIV para descubrir qué crisis puedan abarcar a ámplias capas de población y a muchos territorios. Contribuye a esta situación el hecho que, desde principios del siglo XI, los panificables son la base de la dieta en muchas poblaciones, mientras que los productos silvopastoriles y hortícolas adquieren cada vez menos importancia. Puede haber contribuido a ello la decadencia y degradación del bosque mediterráneo ${ }^{25}$.

\footnotetext{
${ }^{23}$ P. BentTo I Monclús, Clergues, op. cit., p. 116

${ }^{24}$ ACA. R.B. III, núm. 191.

${ }^{25}$ Cfr. J. GunzBerg Moll, Crisis, op. cit., pp. 987 y ss.
} 
Aspecto destacable en las ciudades de Barcelona, Girona y la Seu d'Urgell es que ya disponían de un volumen importante de población la cual, en épocas de crisis, no se la podía alimentar con los recursos del territorio.

Una cuestión que puede plantearse es saber como superaban los habitantes los periodos de hambrunas. Por desgracia, los documentos nada dicen sobre este particular, aunque sí lo sabemos para siglos posteriores: la importanción de alimentos, mayoritariamente trigo, desde otras zonas mediterraneas. 


\section{APÉNDICE DOCUMENTAL}

1092, diciembre, 22.

Petronila vende a Ramon Llopart y a Bernat Otger tres cuartas partes de una casa situada en el suburbio de Barcelona, junto a los muros, por 25 mancusos, a causa del hambre que padecen.

ACB, 1-4-311.

"...anc namque vendicionem necessittate famis vobis facio, ne ego et filii mei fame intolerabili moriamur".

2

1093, febrero, 27

Adalet y sus hijas Adalet y Guilia venden a Guillem y a su mujer Solestén dos piezas de tierra situada en el condado de Barcelona, en el Vallès, en la parroquia de Sant Salvador de Polinyà, un lugar llamado Omet, por el precio de una medida de trigo ${ }^{26}$.

ADB, carp. 3A, perg. núm. 165 .

"...sic vendimus vobis supranominata terra ab integrum, quantum abemus cum exiis et regressiis earum in precium migera .I. de blad...".

26J. Alturo I Perucho, L'arxiu antic de Santa Anna, doc. núm. 132. 
1093, marzo, 20.

Ponç Ramon, su mujer Ermergarda, sus hijos Guillem y Arnau, y un pariente llamado Guillem Bernat permutan a los canónigos de la Seo unas tierras con casa situadas en Aiguatèbia, a cambio de un animal de tiro y 10 modios de centeno, a causa de la insoportable hambre que aflige a toda la tierra'.

ACU, perg. núm. 711.

"Sicut prenominata sunt omnia et terminantur a prelibata quadrina climata, propter fames valida que surrexit per circuitum nostrum insuperabilia in omni terra ab Italia usque ad Sanctum Iacobum Gallecia, ...".

1094, enero, 15.

Bonfill Esteve cede a la Seo de Barcelona, por un año, el usufructro de su alodio, a cambio que la canónica le mantenga y le vista, a causa de la gran calamidad que padece.

ACB, LA I, núm. 409.

"...ingruente inedie nimia calamitate..."

1094, marzo, 1.

Guillem Bonfill y su mujer Nevia venden un alodio situado en el territorio de Barcelona, en el lugar llamado Clot de la mel, cerca de los muros antiguos, por 74 mancusos, a causa de la pobreza y el hambre.

ACB, LA I, núm. 496.

${ }^{27} \mathrm{C}$. BARAUT, Els documents, op. cit. núm. 1102. 
"...propter inopiam famis ut unde vivamus nos et infante nostri..."

1094, marzo, 19.

Los esposos Dalmau y Domènica dan a su hijo Guillem Dalmau y a su esposa Maiasens unas casas situadas en Girona y una viña, para poder salir de la miseria $^{28}$.

ACG, perg. ss.IX-XII, carp. 3, núm. 112.

"... ut cartam donationis fecissemus tibi sicuti et facimus ut eripiatis nos a miseria famis, sitis, frigoris et nudiatis".

1094, mayo 19.

Onofret, Guillem y Dom Bernat venden a Pere Umbert, unas viñas situadas en el territorio de Barcelona, en Esplugues, por 30 onzas de oro, a causa de su gran necesidad.

ACB, LA IV, núm. 121.

"... deinde cogente nimia necessitate...".

1095, febrero, 12.

Blancussa vende a Ponç Guillem y a su mujer Ermessenda unas tierras y casas, situadas en Sant Cristòfol de Llambilles, por el precio de un sueldo y una mediana de trigo, a causa del hambre que padece ${ }^{29}$.

${ }^{28} \mathrm{Cfr}$. R. MARTí, Col·lecció, op. cit., doc. núm. 451.

${ }^{29}$ Cfr. R. MARTí, Col.lecció, op. cit., doc. núm. 457. 
ADG, Pia Almoina Llambilles, núm. 82.

"... quod ego Blancucia accipio a vobis libenter per necessitatem famis".

1095, agosto, 14 .

Guillem Miró dona a la canónica Santa María de la Seo de Urgell sus bienes integrados por una tierras situada en el condado de Urgell, en el término de Sant Fruitós, y de unos molinos situados en Tost, a cambio que la canónica le mantenga durante su vida.

ACU, perg. núm. 739.

"... in tali conventione ut habeam in cannonica Sancte Marie victum et vestitum et ea que mihi necessaria sunt dum vixero."

\section{0}

1096, agosto, 2.

Ponç Ramon y su mujer Ermergarda venden una tierra situada en el condado de Cerdaña, en el pago de Llivia, cerca de la población de Palau, en Salàs, por el precio de 23 sueldos a causa del hambre que padecen ${ }^{31}$.

$$
\text { ACU, perg. núm. } 747 .
$$

"...sic vindimus nos tibi alodem nostrum iam dicto ab integrum propter sterilitatem fammis,..."

${ }^{30}$ C. BARAUT, Els documents, op. cit., doc. núm. 1133.

${ }^{31}$ Els documents, op. cit., núm. 1144. 
1097, febrero, 20

Bernat Radol y su mujer Biliarz junto a Pelegri venden a Ramon Arnau una viña situada en la Cerdaña, en la "Petra Rasin", en la villa de Bor, por el precio de un modio de trigo ${ }^{32}$.

ACU, perg, núm. 750.

"...vindimus nos tibi prescripta vinea ab integrum in precio modio .I. de blad..."

1116, junio, 30 .

Salomon Eriman y su mujer María dan en herencia a su hijo Guifré una casa situada en el suburbio de Barcelona, en el lugar dels Archs, junto al Palacio Condal menor, a causa de los muchos servicios que prestó cuando hubo las grandes hambrunas en el territorio de Barcelona.

ACA, Ramon Berenguer III, perg. núm. 191.

"...propter multis beneficiis et serviciis, quem nobis fecistis et facis et in antea feceris et quod cunctum tuum avere quod umquam potuisti abere totum in nobis expendisti per plurimas fames qui fuerunt in patria Barchinone, ubi non fuit qui succurrisset nobis nec valuisset nullus nisi Deus et tu, filium nostrum...".

${ }^{32} \mathrm{C}$. BARAUT, Els documents, op. cit., doc. núm. 1148. 